\title{
A PRESSÃO PARA EXPANSÃO DO DIREITO À EDUCAÇÃO INFANTIL POR MEIO DE TERMOS DE AJUSTAMENTO DE CONDUTA*
}

\author{
Marina Feldman ${ }^{1}$ (1) \\ Adriana Aparecida Dragone Silveira² ${ }^{2}$
}

\begin{abstract}
RESUMO: Apresenta-se mapeamento do cenário de exigibilidade extrajudicial do direito à educaçáo infantil, buscando compreender como a atuação do Ministério Público incide na efetivação deste, analisando em específico o caso do Paraná. A partir da constatação de que 37 municípios no estado apresentam firmamento de termos de ajustamento de conduta para ampliação de vagas na educação infantil entre 2008 e 2016, buscam-se causas e efeitos do uso dessa ferramenta. Também se procura, em diálogo com os documentos, compreender como os acordos tratam o acesso à etapa e propóem controlar o cumprimento do acordado. Como conclusóes, evidencia-se cenário de incidência da política institucional desse ator para a elaboraçáo dos acordos, ainda que seus efeitos se mostrem limitados.
\end{abstract}

Palavras-chave: Educação infantil. Judicialização da educação. Ministério Público. Termo de ajustamento de conduta.

\section{THE PRESSURE TO EXPAND THE RIGHT TO EARLY CHILDHOOD EDUCATION THROUGH THE CONDUCT ADJUSTMENT TERMS}

\begin{abstract}
This article maps the scenario of the extrajudicial enforcement to the right to Early Childhood Education, seeking to understand how the Public Prosecution Office's activity influences the effectiveness of such right, analyzing the specific case of Paraná state. From the observation that Conduct Adjustment Terms were signed in 37 municipalities between 2008 and 2016, in order to expand provision of Early Childhood Education, the authors seek causes and effects of using this tool. They also aim at understanding, in dialogue with the
\end{abstract}

\footnotetext{
*Este artigo é parte do projeto de pesquisa intitulado "Efeitos da atuaçâo do sistema de justiça no direito à educação infantil: um estudo da judicialização da política educacional em três estados brasileiros", financiado pelo Conselho Nacional de Desenvolvimento Cientifico e Tecnológico (CNPq), chamada CNPq/ MCTI no 25/2015. Também constitui parte de dissertação de mestrado, financiado por meio da bolsa de pós-graduaçáo da Coordenaçáo de Aperfeiçoamento de Pessoal de Nível Superior (Capes).

${ }^{1}$ Rutgers University - Nova Jersey, Estados Unidos. E-mail: marina.feldmans@rutgers.edu

${ }^{2}$ Universidade Federal do Paraná, Departamento de Planejamento e Administraçáo Escolar, Núcleo de Políticas Educacionais - Curitiba (PR), Brasil. E-mail: adrianadragone@yahoo.com.br

DOI: 10.1590/ES0101-73302018186306
} 
documents, how the problem of access is treated in these agreements, along with the compliance mechanisms used. The conclusions point out to the incidence of this entity's institutional policy in the agreements signed, even though the effects appear to be limited.

Keyword: Early childhood education. Education litigation. Public Prosecution Office. Conduct adjustment term.

\section{LA PRESSION POUR ÉTENDRE LE DROIT À L'ÉDUCATION DE LA PETITE ENFANCE À TRAVERS DES TERME D'AJUSTEMENT DE CONDUITE}

$R E S U M E ́$ : Cet article présente la cartographie du scénario des exécutions extrajudiciaires liées au droit à l'éducation dans l'enfance, en essayant de comprendre comment le travail du bureau du ministère public se concentre sur la réalisation de ce droit, d'après une analyse du cas de l'etát du Paraná. De la constatation que 37 municipalités de l'état ont signé les Termes d'Ajustement de Conduite pour augmenter les postes vacants pour l'éducation dans la petite enfance entre 2008 et 2016, nous cherchons à comprendre les causes et les effets du phénomène. On vise également, basé sur le dialogue avec les documents, à comprendre comment cette question de l'accès a l'étape est approchée et comment ils proposent de surveiller ce qui a été convenu. Les résultats montrent un scénario d'incidence par la politique institutionnelle del bureau par moyen des accords signés, même si les effets soient considérés limités.

Mots-clés : Éducation dans la Petite Enfance; Légalisation de l'éducation; Ministère Public (MP), Terme d'Ajustement de Conduite.

\section{Introdução}

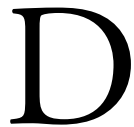

iversos debates sobre direito à educação no Brasil partem da Constituição Federal de 1988 (CF/88), que o assegura como direito de todos e dever do Estado e o consagra como direito público subjetivo ${ }^{1}$ (apud DUARTE, 2004). Também representa o marco em que a educação infantil (EI) passa a constar no rol dos direitos de todas as crianças, obrigando o Estado a provê-la (ROSEMBERG, 2009; VICTOR, 2011). A Lei de Diretrizes e Bases da Educação Nacional (LDB) de 1996 ainda compreende a EI como primeira etapa da educação básica.

Entretanto, após 30 anos, distamos do direito constitucionalmente previsto. Grande parcela segue tendo seu acesso negado à EI, havendo padróes de privação desiguais (INEP, 2015; ROSEMBERG, 1996), mesmo com a doutrina de proteção integral, prevista no Estatuto da Criança e do Adolescente (ECA) de 1990 (BRASIL, 1990). 
Em tal cenário, observamos que uma via de exigibilidade mobilizada é a do sistema de justiça. Uma série de pesquisas mostra a incidência da temática da EI no âmbito judicial (SILVEIRA, 2006; 2015; VICTOR, 2011; ZANDER, 2015; SILVA, 2016), o que se apresenta com clareza após decisão do Supremo Tribunal Federal (STF) em 2005, que estabelece que o entendimento de direito público subjetivo se estende para esse tipo de ensino, caracterizado como elemento do núcleo intangível do direito à educação (TORRES, 2009; RIZZI \& XIMENES, 2010).

Em tal cenário, destaca-se o Ministério Público (MP), colocado pelo ECA/1990 em papel central na proteção da infância, atuando na proteção do direito à EI em diversos contextos (BRAGA, 2010; DAMASCO, 2008; SILVEIRA, 2006; 2015; SILVA, 2015). A instituição tem seu papel alterado durante a redemocratizaçáo do país, aproximando-se da função de representante da sociedade e defensora da cidadania com centralidade na área dos direitos transindividuais, que agrupam interesses coletivos, difusos e individuais homogêneos (SILVA, 2001; SADEK, 2009).

Tal conjunto de direitos passa a ser reconhecido nesse contexto histórico, sendo criadas estratégias para sua exigibilidade (SILVA, 2001; FRISCHEISEN, 2000; SANTOS, 2011; RODRIGUES, 2002). Entende-se que a tutela de interesses transindividuais, por caráter amplo, pode ter relevante incidência em políticas públicas.

Nesse sentido, o ECA/1990 prevê o uso de termos de ajustamento de conduta (TACs) para garantia dos direitos da infância, sendo instrumento possível para adequação da ação de entes governamentais a previsóes legais. Segundo Frischeisen (2000), o TAC é um instrumento que permite considerar questôes orçamentárias e temporais para a efetivação de políticas, ainda que não possa permitir violaçóes de direitos. Tal mecanismo também representaria economia processual e espaço de diálogo entre poder público e MP (RODRIGUES, 2002; VIOLIN, 2013).

No estado do Paraná, o MP, por meio do Centro de Apoio Operacional às Promotorias de Justiça da Criança e do Adolescente - Área da Educação (Caopcae/Educação), tem atuação proeminente na área da EI. Uma das principais ações é um projeto estratégico da instituição para a área de educação - debatido a partir de 2009, divulgado em 2011 e encerrado em 2016 - que visa sensibilizar promotores de justiça sobre a problemática do atendimento na etapa. O projeto estratégico do MP para a ampliação do atendimento na EI se relaciona à Emenda Constitucional 59/2009 (EC 59/2009) e se vincula ao déficit de oferta no estado, que em 2010 tinha atendimento de $24 \%$ em creches e $64 \%$ em pré-escolas, comparado a cerca de 19 e $85 \%$ no total do país (IBGE, 2016; INEP, 2016). Trata-se de atendimento pouco acima da média nacional no caso da creche e significativamente abaixo para pré-escola. 
Nesse cenário, há indicação do Caopcae/Educação para a realização de acordos entre os promotores de justiça e as gestóes municipais, com o firmamento de TACs, evitando o uso da via judicial, considerando o tempo de julgamento de uma ação nos tribunais e a imprevisibilidade de resultados. Com isso, há significativa incidência do firmamento de TACs no estado, com 39 casos, em paralelo a 29 açóes civis públicas ingressadas no judiciário pelo MP. Nesse cenário, busca-se compreender de que forma a atuação do MP, pela via dos TACs, incide na efetivaçâo do direito à educação infantil. Intenta-se analisar por que o instrumento vem sendo usado amplamente na esfera do direito a essa educação, qual a abordagem da problemática de acesso e os mecanismos de cumprimento e quais os efeitos em termos de efetivação do direito.

Assim, traça-se cenário de como os TACs têm sido estratégia do MP na temática no Paraná. Para tal fim, o acesso aos documentos foi realizado por contato com a instituição por meio do Caopcae/Educação e da Subprocuradoria-Geral de Justiça para Assuntos de Planejamento Institucional (Subplan). Também foi feita conferência de dados do Portal de Transparência do MP-PR ${ }^{2}$. A presente análise considera informaçóes obtidas desse portal até o dia 29 de junho de 2016, totalizando 39 TACs para ampliação de vagas na EI em 37 municípios, considerado o caso de Telêmaco Borba, que apresenta três TACs.

Após mapeamento dos TACs existentes, traça-se relação com variáveis institucionais relacionadas ao MP e dados de atendimento na etapa. Opta-se por trabalhar com a taxa de atendimento no ano de 2010 e com os números absolutos dos anos de 2010 a 2015 consideradas as limitaçóes no cálculo do atendimento (ROSEMBERG, 2015). Quanto ao conteúdo, buscam-se aproximaçóes e distanciamentos entre os instrumentos de cada contexto. Em seguida, compara-se o acordado no TAC e a ampliação de vagas ao longo do período.

\section{Cenário da exigibilidade extrajudicial da educação infantil no Paraná}

Os 37 municípios com TACs firmados entre executivo e promotoria de justiça representam número significativo, ainda que pequeno, se considerados os 399 municípios do estado e a carência de atendimento existente. Percebe-se, no Gráfico 1, que a distribuição temporal mostra incidência do projeto estratégico do Caopcae/Educação, visto haver apenas um TAC firmado antes de 2009.

Mais além, ainda que a distribuição temporal demonstre incidência do projeto institucional, a distribuição geoespacial dos municípios localizados (Figura 1) parece reforçar que a independência funcional dos promotores de justiça leva a padróes de atuação distintos, mesmo que haja poder de influência do Caopcae/Educação. Assim, há concentração dos municípios com TACs nas regiôes sudoeste, norte e leste, justamente aquelas em que se concentra padrão de atendimento menos crítico 


\section{Gráfico 1}

Termos de ajustamento de conduta firmados para ampliação de vagas na educação infantil por ano (2008-2016).

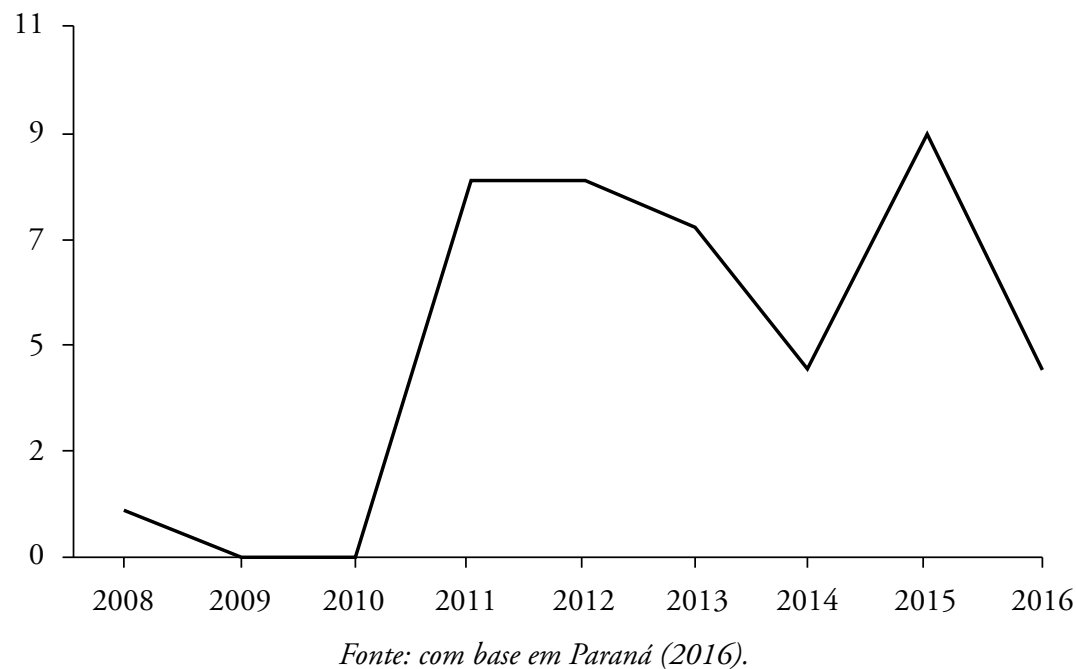

Figura 1

Localização dos municípios com termo de ajustamento de conduta firmado para ampliação de vagas na educação infantil.

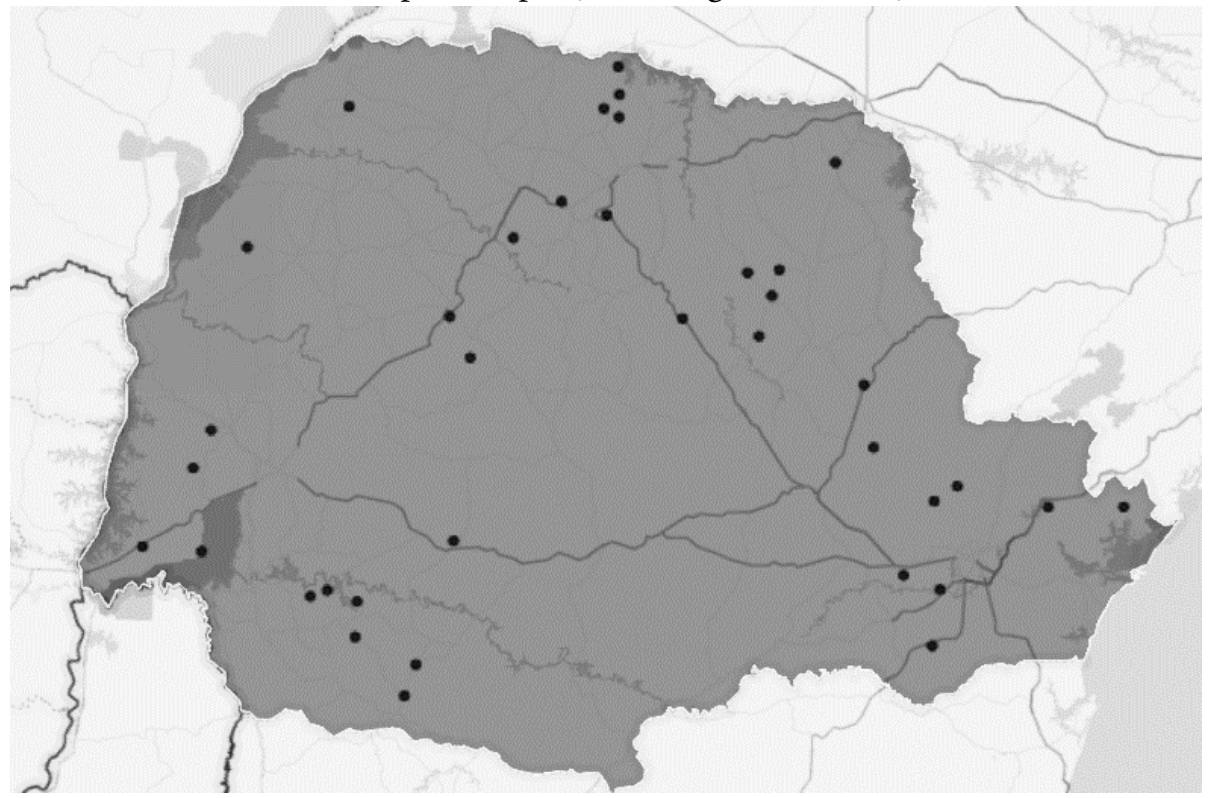

Fonte: com base em Paraná (2016). 
(SILVEIRA \& GONÇALVES, 2014). Tal não quer dizer que certos municípios com baixo atendimento não estejam sendo atingidos pelo fenômeno, o que será retomado na subseção que segue.

Entretanto, o dado corrobora a ideia de Silva (2001) de que a abrangência da legislação e a independência funcional geram diversos perfis de atuação na defesa dos interesses transindividuais. Tais perfis podem ainda estar relacionados às condiçôes de trabalho nas comarcas, aos padróes de atendimento na etapa ou à opção pelo ingresso de açóes judiciais em detrimento da via extrajudicial.

Também é possível indicar que a maioria dos municípios com TAC são de pequeno porte ${ }^{3}$, o que está em partes relacionado a maior presença de municipalidades desse perfil no estado. Além disso, aponta possível maior incidência do MP nesses municípios, o que pode estar relacionado ao tensionamento acirrado entre poder público e promotoria de justiça, a qual representa poder significativo em cidades menores (SILVA, 2001). Assim, o firmamento dos TACs, ainda que relacionado a possíveis carências de atendimento e demandas da população, não parece possuir relação de causalidade com baixo atendimento na etapa. Tal se observa na Tabela 1 , que traz municípios por faixas de atendimento, considerando-se o estado e as cidades com TAC firmado.

Percebe-se que apenas 2,7\% dos municípios com TAC firmado para pré-escola está na faixa de 0 a $30 \%$ de atendimento, ainda que tal faixa represente $11,5 \%$ dos municípios no estado. Quanto à creche, ainda que os TACs se concentrem em municípios com faixas de atendimento mais baixas, pode-se indicar que $40,5 \%$ dos municípios com TACs firmados para a subetapa se encontravam

\section{Tabela 1}

Municípios por faixas de atendimento em 2010.

\begin{tabular}{l|c|c|c|c|c}
\hline $\begin{array}{l}\text { Faixas de } \\
\text { atendimento } \\
\text { de creche (\%) }\end{array}$ & $\begin{array}{c}\text { Quantidade } \\
\text { de municípios } \\
\text { com TAC }\end{array}$ & $\begin{array}{c}\text { Quantidade } \\
\text { de municípios } \\
\text { no Paraná }\end{array}$ & $\begin{array}{c}\text { Faixas de } \\
\text { atendimento } \\
\text { de pré-escola } \\
\mathbf{( \% )}\end{array}$ & $\begin{array}{c}\text { Quantidade } \\
\text { de municípios } \\
\text { com TAC }\end{array}$ & $\begin{array}{c}\text { Quantidade } \\
\text { de municípios } \\
\text { no Paraná }\end{array}$ \\
\hline 0 a 10 & 21,6 & 19,5 & 0 a 15 & 0,0 & 3,5 \\
\hline 11 a 20 & 32,4 & 42,4 & 16 a 30 & 2,7 & 8,0 \\
\hline 21 a 30 & 29,7 & 24,8 & 31 a 50 & 32,4 & 28,0 \\
\hline 31 a 40 & 10,8 & 8,3 & 51 a 65 & 27,0 & 24,3 \\
\hline 41 a 50 & 5,4 & 4,0 & 66 a 80 & 8,1 & 17,8 \\
\hline 50 a 62 & 0,0 & 1,0 & 81 a 94 & 10,8 & 12,3 \\
\hline & & & 95 a 126 & 18,9 & 6,0 \\
\hline Total & $37(100 \%)$ & $399(100 \%)$ & & $37(100 \%)$ & $399(100 \%)$ \\
\hline
\end{tabular}


em 2010 acima da média estadual de atendimento. Não se pretende dizer que tais municípios não tenham demanda por vagas, mas sim que a incidência dos TACs não parece ser consequência do baixo atendimento.

Nesse sentido, é relevante a reflexão de Berclaz (2010) sobre a necessidade de equilíbrio entre independência funcional e unidade institucional do MP, questão também trazida pela promotora de justiça responsável pelo projeto institucional. Segundo Berclaz (2010), constitui-se como problema central na atuação do MP a dependência existente entre a realização dos objetivos institucionais, em especial no âmbito extrajudicial, e o voluntarismo do promotor de justiça. Segundo o autor, a atuação institucional deveria considerar objetivos estratégicos estabelecidos democraticamente, a partir de dados estatísticos e demandas da população.

A despeito disso, o cenário mostra baixa uniformidade institucional. De todo modo, náo se pode afirmar que ela fosse um bom indicativo, visto que poderia demonstrar falta de diálogo dos promotores de justiça com a realidade em que se inserem e que apresenta necessidades específicas. Entretanto, partese da constatação de uma atuação desigual na temática ao redor do estado, que não parece derivar das condiçóes de cada localidade. Um elemento relevante para empreender análise de variáveis institucionais do MP nas comarcas com TAC é o tipo de jurisdição em que os TACs foram firmados, em comparação com o total de comarcas no estado (Tabela 2).

Esclarece-se que o MP é dividido em comarcas de diferentes perfis, segundo divisão do poder judiciário no estado. As de entrância inicial se compóem de um único juízo ou vara, com competência genérica, enquanto as de entrâncias intermediária e final se compóem de duas ou mais varas, já especializadas em relaçâo às competências de julgamento. Como as comarcas de entrância inicial contam geralmente com um único promotor de justiça responsável por todas as matérias de direito, a atençáo às necessidades da populaçáo residente na localidade em relação à EI é dividida com outras demandas, o que corrobora uma possível relação entre variáveis institucionais e o firmamento de TACs nessa temática.

Tabela 2

Comarcas no estado com e sem termo de ajustamento de conduta, por tipo de entrância.

\begin{tabular}{l|c|c}
\hline Tipo de entrância & $\begin{array}{c}\text { Percentual das } \\
\text { comarcas com TAC }\end{array}$ & $\begin{array}{c}\text { Percentual das } \\
\text { comarcas no estado }\end{array}$ \\
\hline Entrância inicial & $19,0 \%$ & $56,0 \%$ \\
\hline Entrância intermediária & $54,0 \%$ & $33,4 \%$ \\
\hline Entrância final & $27,0 \%$ & $10,6 \%$ \\
\hline & $100,0 \%$ & $100 \%$ \\
\hline
\end{tabular}

Fonte: com base em Paraná (2016). 
Nota-se predominância de TACs em comarcas de entrância intermediária, com número significativo nas de entrância final e pequeno nas de inicial. Tal padrão se mostra inverso à distribuição quantitativa de comarcas, que são, em sua maioria, de entrância inicial. Isso indica que possivelmente o firmamento do TAC estaria mais relacionado à condição das promotorias em questấo do que às taxas de atendimento na etapa, já que em comarcas de entrância inicial promotores concentram as atribuiçóes, enquanto nas intermediárias as dividem com ao menos um promotor, especializando-se nas de entrância final. Assim, os promotores parecem firmar mais TACs nas comarcas em que têm menor rol de atribuiçóes.

É importante indicar que as comarcas de entrância incial analisadas são sediadas em municípios de pequeno porte, enquanto as de entrância intermediária encontram-se nos de pequeno e médio portes. Já as comarcas de entrância final com TACs se encontram em municípios de grande, médio e pequeno portes, sendo que, no útimo caso, apenas em municípios classificados pelo Instituto Brasileiro de Geografia e Estatística (IBGE, 2011) como pequeno porte 2. Vale dizer ainda que 11 dos 20 municípios com TACs firmados em comarcas de entrância intermediária não são sede da comarca em questão, sendo quase exclusivamente municípios de pequeno porte 1 . Tais informações ajudam a entender por que, mesmo sendo a maioria dos TACs firmados em municípios de pequeno porte, há predominância nas comarcas de entrância intermediária.

É relevante indicar que a maioria das comarcas no estado inclui mais de um município, sendo um deles a sede. Dos 37 municípios com TACs, 16 não eram sede de sua comarca, sendo que 290 cidades no estado não são sede de comarca, apontando, mais uma vez, para uma relação não necessariamente condizente ao cenário do estado. Tal parece indicar maior esforço dos promotores de justiça nos municípios em que se encontram alocados, o que dialoga com a função de atendimento ao público, que torna relevante a proximidade geográfica com a população (SILVA, 2001). Tais dados reforçam a hipótese explicativa das condiçóes institucionais como influência para o firmamento do TAC.

Destaca-se também que, entre os sete TACs encontrados em comarcas de entrância inicial, três são atribuídos ao mesmo promotor, enquanto estava alocado na comarca de Curiúva. Nesse sentido, pode-se destacar que, tanto na comarca de Curiúva quanto nas de Campo Mourão, Dois Vizinhos e Porecatu, houve firmamento de mais de um TAC por um mesmo promotor, cada um deles em um município da comarca.

O caso da comarca de Curiúva se destaca por englobar os dois únicos municípios com TAC que não são sede de comarca e estão em uma entrância inicial. Nela, temos três documentos idênticos, coincidindo a data de firmamento e replicando a exata formulação do TACs firmados em outra localidade. Assim, parece corroborar a relevância de variáveis institucionais, já que o único caso de municípios com TAC que não são sede de comarca e estão em entrância inicial mostra a reprodução de mo- 
delos externos. Também nos casos de Dois Vizinhos e Porecatu, municípios de uma mesma comarca de entrância intermediária, aparece a exata formulaçáo de modelo do Caopcae/Educação, com breves referências a indicadores dos municípios. Somente no caso da comarca de Campo Mourão se percebe que o TAC do município sede e o do de Luiziana foram formulados separadamente pela mesma promotora.

Nesse sentido, vale um olhar ao conteúdo do modelo enviado pelo Caopcae/Educação. Em sua atuação estratégica, o centro enviou às promotorias de justiça um roteiro de atuação e um conjunto de modelos de documentos. Entre estes, está a portaria de instauração de procedimento preparatório, ofícios ao executivo e legislativo municipais e ao conselho tutelar para levantar dados sobre planejamento municipal e oferta de vagas na EI e informar sobre a existência do procedimento como possível forma de pressão sobre a administração. Também foi remetido diagnóstico da localidade, com levantamento da oferta e do quantitativo de vagas a serem criadas para adequação legal.

Ademais, foi enviado modelo de TAC (SILVEIRA \& GONÇALVES, 2014) contendo fundamentação sobre a exigência legal de garantia do direito à EI e pedido de atendimento de todas as crianças de 4 e 5 anos, com atendimento da demanda manifesta de imediato e $25 \%$ da demanda absoluta remanescente a cada ano (PARANÁ, 2011). O modelo ainda traz exigência de envio de documentos comprobatórios ao $\mathrm{MP}$ e formas de reorganização de recursos orçamentários para o cumprimento.

Nesse modelo também consta a exigência de que peças orçamentárias sejam remetidas para o MP antes de aprovadas e a necessidade de contratação de servidores por concurso público quando náo disponíveis nos quadros do município. Também é prevista multa diária de $\mathrm{R} \$ 1.000,00$ a ser recolhida ao município pelo prefeito (PARANÁ, 2011). Como veremos adiante, as formulaçóes do Caopcae/Educação foram utilizadas completa ou parcialmente em diversas comarcas.

Em termos de padronizaçáo, vale ressaltar que a maioria absoluta dos TACs possui início idêntico, retirado do modelo do Caopcae/Educação, em que constam consideraçóes legais que levam ao firmamento, sendo que em apenas três municípios aparecem elementos referindo-se ao contexto local ou a fontes complementares de embasamento. Após a fundamentação, aparece maior variação, ainda que com certos padróes - um deles, vinculado ao modelo do Caopcae/Educação, é a priorização da pré-escola. O projeto estratégico não faz distinção, a princípio, entre o atendimento nas subetapas. Entretanto, o modelo enviado traz solicitação de universalização da pré-escola, secundarizando a demanda por creche.

Assim, a orientação do Caopcae/Educação induz priorização da pré-escola, sendo que 14 dos TACs analisados trazem tal formato. Entende-se que a priorização, ainda que questionável, é coerente ao cenário estadual, com apenas $64 \%$ de atendimento na subetapa, marcando distância das metas nacionais, especialmente quando considerados os prazos estabelecidos legalmente. Ainda se 
observam 13 TACs que não diferenciam subetapas e dois que dizem respeito apenas à creche. Outros seis municípios têm acordado o atendimento da demanda absoluta - entendida como o total da população na faixa etária — em pré-escola e manifesta em creche, sendo que três especificam o número de vagas.

Em um nível de maior detalhamento, os pedidos dos TACs indicam outros padrões que se relacionam ao modelo enviado pelo Caopcae/Educação, além de alguns cuja origem é difícil aferir, como a referência, em cinco TACs, à oferta "integral no que se refere à estrutura, autorização de funcionamento, profissionais, material didático, merenda escola e acomodaçôes" (PARANÁ, 2015). Tal padronizaçáo não decorre do modelo, porém é possível indicar que o compartilhamento entre promotores dos textos utilizados pode estar relacionado à estrutura do Caopcae/Educação.

Para além do pedido central e do embasamento, o padrão mais repetido refere-se às questóes orçamentárias, sendo que 22 dos TACs apresentam a formulação idêntica ao modelo do Caopcae/Educação:

Os recursos necessários à implementaçáo do presente termo de COMPROMISSO DE AJUSTAMENTO DE CONDUTA serão obtidos junto ao orçamento destinado à Secretaria Municipal de Educação, se necessário, através do remanejamento dos recursos constantes do orçamento em execução, que poderão ser avocados de áreas não prioritárias e/ou, se necessário, por intermédio da abertura de créditos orçamentários suplementares ou especiais (PARANÁ, 2014a).

Além disso, aparece a necessidade de prever verbas para o cumprimento do acordado nas peças orçamentárias, enviando-as ao MP antes da aprovação pelo legislativo, o que consta no modelo e em 24 casos. Apenas quatro TACs não fazem consideraçóes orçamentárias. Em meio às consideraçóes sobre alocação de recursos, tende a aparecer a necessidade de contratação de servidores via concurso público, o que também aparece de modo padronizado em 22 dos 24 casos que debatem orçamento.

Ademais, outros quatro TACs trazem consideraçóes específicas sobre contratação de docentes, como no caso de Campo Mourão, que o faz após afirmar a necessidade de garantir a qualidade da oferta (PARANÁ, 2014b). No âmbito do controle visando ao cumprimento do acordado, além da remissáo das peças orçamentárias, aparece em 12 casos o envio das listas de espera atualizadas ao MP. Sete destes também tratam do controle social, através da obrigação de divulgação pública da lista.

Mais além, todos os TACs analisados estabelecem um tipo de multa, de $\mathrm{R} \$ 100,00$ diários a 10.000 unidades fiscais de referência (Ufirs) por mês. Em grande parte (15), a multa deve ser paga para o Fundo Especial da Infância e Adolescência, mas em 18 delas a multa deverá ser paga "ao município". Nestas náo há indicação de que tal verba seja gasta em área específica ou de que sua destinação seja decidida pelo Conselho dos Direitos da Criança e do Adolescente, conforme previsto no ECA/1990. Afora a problemática de se retirar verbas do erário público para fazer cumprir algo que depende deste (VIOLIN, 2013), soa ambíguo o pagamento 
pelo município a seus próprios cofres. Quanto à cobrança de multa pessoal ao gestor, sugerida no modelo do Caopcae/Educação, esta aparece em apenas três casos.

Ainda no que se refere a penalidades, cabe destacar os casos de Campo Mourão e Toledo, em que há especificação de multas ao município no caso de crianças que tenham sua posição na lista de espera alterada sem respeito aos critérios do TAC ou de crianças que deixem de frequentar os Centros Municipais de Educação Infantil e não tenham a vaga cancelada. Ainda nesses TACs, há determinação de que crianças com menos de $60 \%$ de frequência percam a vaga. Nos dois casos, também aparecem critérios e prazos de adequaçáo e multa referentes à adequada quantidade de alunos por turma, segundo critérios dos Conselhos Estadual e/ou Municipal de Educação, indicando preocupação com as condiçôes de qualidade na oferta.

Tais TACs trazem, por um lado, a possibilidade de que a criança perca acesso ao direito em caso de baixa frequência, contrariando a concepçáo desta como sujeito de direito. Por outro, carregam a potencialidade de olhar as condiçôes de oferta no momento de abertura das vagas, dialogando com as indicaçóes de Rosemberg (1996), que refletem sobre a possibilidade de uma expansão quantitativa e qualitativa.

Rosemberg (1996) enxerga uma expansão caótica no país, em que a oferta por diversas vias, como instituiçôes públicas, privadas e conveniadas, gera a possibilidade de um conjunto de serviços desiguais. Nesse diapasão, pode-se indicar que seis TACs indicam que, no caso da incapacidade do município de realizar a oferta das vagas, pode-se realizar atendimento pela via do conveniamento, havendo alusóes inclusive à compra de vagas na iniciativa privada. Vale dizer que a promotora responsável pelo Caopcae/Educaçáo reforça a possibilidade de conveniamento como solução provisória para a questão.

Outros indicativos de condiçóes de qualidade aparecem em cinco TACs, que indicam locais onde as vagas serão abertas, se o serão pela construção de edifícios ou pelo uso de espaços existentes. Mais cinco ainda fazem referência às adequadas condiçōes de infraestrutura sem explicar quais sejam ou quem as determinará. Considera-se tal tipo de observação relevante para uma expansão quantitativa aliada a padrões de qualidade. Entende-se que o TAC, como instrumento negociado, com prazos supostamente razoáveis, abre espaço para consideraçôes referentes às condiçóes da oferta. Tal preocupação, entretanto, parece pouco presente, além de estar aberta a questionamentos em nível de interferência na discricionariedade do administrador.

Assim, a análise empreendida mostra alto grau de padronização nos documentos, sendo poucos os casos de detalhamento relacionado ao contexto de firmamento. Ainda em termos de conteúdo, percebe-se uma série de mecanismos voltados ao cumprimento, como a cobrança de multas e o envio de peças orçamentárias e documentos comprobatórios. A ideia de controle social pela população não é central, mas aparece implícita em algumas formulações. Em termos das causas do firmamento, aparecem indicativos de que os TACs estejam relacionados 
às condicionantes institucionais do MP local mais do que à defasagem no atendimento, ficando em aberto a hipótese explicativa ligada ao perfil do promotor, que deve ser analisada em casos específicos. Resta analisar efeitos, a partir de olhar as demandas centrais dos TACs, em paralelo com dados de matrícula na etapa, traçando consideraçóes sobre a ampliação do atendimento.

\section{Considerações a partir de indicadores de atendimento}

Considera-se os 14 municípios com TACs contendo pedidos exclusivamente de ampliação de vagas na pré-escola como baliza relevante para compreender efeitos, por tratarem da maior parte dos TACs firmados anteriormente a 2015, ano considerado para cálculo do crescimento no número de vagas, conforme se observa na Tabela 3. Os dados indicam que, apesar da priorização da pré-escola, o crescimento das matrículas nesses municípios tende a ser maior na creche entre 2010 e 2015 , com média de crescimento de $71,9 \%$, sendo que a média dos 37 municípios estudados é de 57,9\%.

Sendo retirados do cálculo dois municípios com TAC firmado a partir de 2015 , temos ainda $74 \%$ de crescimento em creche e $12,08 \%$ em pré-escola. Assim, se por um lado os dados indicam que a priorização feita pelo MP não afetou a ampliação da provisão de creche, por outro mostram efeitos limitados dos acordos, que buscavam incidir na oferta de pré-escola. Tais dados também podem indicar pressão social da população em torno da ampliação da creche, não necessariamente descolada do envolvimento da promotoria no tema, mas remetendo a campo de tensionamentos mais amplo.

Tal quadro também pode estar relacionado às discrepâncias nos modos de lançamento dos dados pelas secretarias municipais, conforme indicado por Rosemberg (2015). Mais além, é possível que o uso de texto padronizado, retirado do modelo enviado pelo Caopcae/Educação, tenha levado à formulação de TACs que pouco dialogaram com as realidades municipais, indicando relevância de diagnóstico prévio.

Não se faz discussão específica dos municípios cujos TACs abordam duas subetapas ou apenas creche, pois ao menos metade destes foi firmada após 2014, não sendo possível relacionar crescimento nas matrículas até 2015 com os TACs. Entre os 37 casos analisados, 20 tiveram TACs firmados até 2013, sendo que nesses casos parece mais plausível relacionar o crescimento nos números de matrículas até 2015 com a atuação do MP. Porém, o crescimento geral de vagas na EI mostra que, entre os municípios com TACs até 2013, há um crescimento de 34,6\%, contra 37,4\% naqueles com TACs após 2014. A existência de 16 casos após 2014 indica possível atuação em caráter emergencial, visto ser o prazo de adequação à EC 59/2009 em 2016. 
Outra possível indicação está no caso de cinco TACs que preveem a abertura de vagas em espaços específicos, sendo todos em municípios de pequeno porte, sem diferenciação entre o pedido para creche e pré-escola. Entre esses casos, vemos um crescimento médio, eliminados casos de firmamento em 2015, de 85,1\% para creche e 24,1\% para pré-escola, conforme consta na Tabela 4. Tais indicativos, ainda que de um número pequeno de casos, podem apontar tanto para efeitos mais significativos de TACs que dão indicaçóes específicas quanto para maior incidência dos promotores de justiça em municípios pequenos (SILVA, 2001). Nesse sentido, calculou-se a média de crescimento de acordo com o porte municipal (Quadro 1), ainda que se tratem de apenas quatro municípios de médio porte e três de grande porte.

Pode-se notar que, no caso das vagas em creche, o crescimento médio varia em sentido oposto ao porte. Já no caso da pré-escola, o padrão não se mantém, mesmo que haja crescimento relevante nos municípios de pequeno porte. Porém, nesse caso, também há crescimento significativo nos três municípios de grande porte analisados. Ainda assim, o quadro geral parece apontar para incidência do processo de judicialização na ampliaçáo de vagas na EI no caso dos municípios menores. Isso pode estar relacionado a um maior espaço de atuação do MP,

Tabela 3

Crescimento no número de matrículas em municípios com termo de ajustamento de conduta de ampliaçẫo de vagas apenas para pré-escola, entre 2010 e 2015.

\begin{tabular}{l|c|c|c}
\hline Município & Ano TAC & $\begin{array}{c}\text { Crescimento de } \\
\text { vagas em creche }\end{array}$ & $\begin{array}{c}\text { Crescimento de } \\
\text { vagas em pré-escola }\end{array}$ \\
\hline Cruzeiro do Iguaçu & 2011 & $0 \%$ & $-13,97 \%$ \\
\hline Sáo Jorge D’Oeste & 2011 & $156,76 \%$ & $37,66 \%$ \\
\hline Boa Esperança do Iguaçu & 2011 & $58,54 \%$ & $18,87 \%$ \\
\hline Luiziana & 2011 & $148,28 \%$ & $62,63 \%$ \\
\hline Porecatu & 2011 & $29,23 \%$ & $17,78 \%$ \\
\hline Florestópolis & 2011 & $148,19 \%$ & $23,43 \%$ \\
\hline Miraselva & 2011 & $166,67 \%$ & $-22,22 \%$ \\
\hline Itambé & 2012 & $51,85 \%$ & $14,69 \%$ \\
\hline Piraí do Sul & 2012 & $-28,80 \%$ & $25,61 \%$ \\
\hline Prado Ferreira & 2012 & $25,53 \%$ & $-9,78 \%$ \\
\hline Ortigueira & 2012 & $51,69 \%$ & $-11,54 \%$ \\
\hline Verê & 2012 & $80,00 \%$ & $1,83 \%$ \\
\hline Guaraqueçaba & 2015 & $75,00 \%$ & $22,54 \%$ \\
\hline Pato Branco & 2015 & $44,25 \%$ & $21,07 \%$ \\
\hline Média de crescimento & & $71,90 \%$ & $13,50 \%$ \\
\hline
\end{tabular}

Fonte: com base em Paraná (2016), Portal da Transparência MP-PR (2016) e INEP (2016; 2015). 
podendo representar força significativa de pressão sobre o poder local, com maior tensionamento entre poder executivo e MP.

Por fim, indica-se que o crescimento no número de matrículas no estado do Paraná entre 2010 e 2015 foi de 33,7\% em creche e $26,1 \%$ na pré-escola. Nos municípios analisados, a média é de 57,9 e 33,7\%, respectivamente, o que pode indicar incidência da existência de promotoria de justiça envolvida em temáticas relativas à EI. Entretanto, quando são separados os municípios com TACs anteriores a 2015, em que tenderia a haver maior incidência do MP nos crescimentos apresentados, temos crescimento de 69,1\% em creche e $23,5 \%$ em pré-escola, o que sustenta a hipótese no caso da creche, mas indica que, no caso da pré-escola, a média foi elevada pelos municípios com TACs posteriores a 2015. Desse modo, os dados trazidos na seçáo mostram indicativos quanto aos efeitos dos TACs, que, em análise inicial, se mostram limitados.

\section{Tabela 4}

Crescimento no número de matrículas em municípios com termo de ajustamento de conduta que especificam as instalaçóes para abertura de vagas entre 2010 e 2015.

\begin{tabular}{l|c|c|c}
\hline Município & Ano TAC & $\begin{array}{c}\text { \% de crescimento - } \\
\text { creche }\end{array}$ & $\begin{array}{c}\text { \% de crescimento - } \\
\text { pré-escola }\end{array}$ \\
\hline Laranjeiras do Sul & 2013 & 61,420 & 7,18 \\
\hline Matelândia & 2013 & 76,080 & 38,54 \\
\hline Campina Grande do Sul & 2014 & 117,680 & 26,68 \\
\hline São Miguel do Iguaçu & 2015 & 5,050 & 91,12 \\
\hline Xambrê & 2015 & 35,440 & 95,59 \\
\hline Média de crescimento & & 59,134 & 51,822 \\
\hline
\end{tabular}

Fonte: com base em PRO-MP (2016), Portal da Transparência MP-PR (2016) e INEP (2016; 2015).

\section{Quadro 1}

Média de crescimento de vagas em creche e pré-escola entre 2010 e 2015, nos municípios com termo de ajustamento de conduta segundo porte municipal.

\begin{tabular}{|c|c|c|c|}
\hline \multicolumn{5}{|c|}{ Creche } \\
\hline $\begin{array}{c}\text { Municípios de } \\
\text { pequeno porte 1 }\end{array}$ & $\begin{array}{c}\text { Municípios de } \\
\text { pequeno porte 2 }\end{array}$ & $\begin{array}{c}\text { Municípios de } \\
\text { médio porte }\end{array}$ & $\begin{array}{c}\text { Municípios de } \\
\text { grande porte }\end{array}$ \\
\hline 68,75 & 56,04 & 52,57 & 40,00 \\
\hline \multicolumn{4}{|c|}{ Pré-escola } \\
\hline $\begin{array}{c}\text { Municípios de } \\
\text { pequeno porte 1 }\end{array}$ & $\begin{array}{c}\text { Municípios de } \\
\text { pequeno porte 2 }\end{array}$ & $\begin{array}{c}\text { Municípios de } \\
\text { médio porte }\end{array}$ & $\begin{array}{c}\text { Municípios de } \\
\text { grande porte }\end{array}$ \\
\hline 27,26 & 42,17 & 17,09 & 40,86 \\
\hline
\end{tabular}

Fonte: com base em INEP (2016; 2015). 


\section{Considerações finais}

Entende-se o estudo de efeitos com desafio, pois a judicialização da educação se insere em teia complexa de relaçóes que advém da multiplicidade de fatores envolvidos em análises de políticas educacionais, mas também da característica do problema de pesquisa, inserido em campo de análise recente (SILVEIRA, 2008). Assim, traçaram-se hipóteses explicativas, sem buscar relaçóes de causalidade unívocas.

Percebe-se uso significativo do TAC no estado, representando estratégia valorizada pelo MP na área da educaçáo. Tal achado amplia o conceito de judicializaçáo de política, entendida por Barroso (2009) como deslocamento de questóes usualmente debatidas pelos poderes eleitos para o âmbito do judiciário. Aqui se compreende que esse deslocamento abarca o sistema de justiça como um todo, incluindo a atuação do MP na esfera extrajudicial, que deve ser considerada em análise mais ampla dos movimentos por trás das políticas públicas. O cenário também permite reforçar a constatação de que a temática da educação vem ganhando centralidade no sistema de justiça. Sendo o MP instituição com autonomia para determinar suas pautas, é perceptível seu direcionamento à temática, que se materializa no nível nacional e, no caso do Paraná, com ênfase na atuação extrajudicial.

A valorização do instrumento do TAC na temática parece relacionar-se a papel indutor do projeto estratégico do Caopcae/Educação. Um dos indicativos da incidência está na padronização dos documentos, indicando atuação questionável em termos de incidência em realidades específicas, que poderia ser mais eficaz a partir de diagnósticos aprofundados. Cabe problematizar que nem sempre os contextos atingidos pelo firmamento dos TACs são os que mais necessitam. O mapeamento do estado mostra que a distribuiçấo dos TACs não coincide com a do baixo atendimento na etapa, tensionando a afirmação de que a judicializaçáo ocorreria na omissão do poder público. Mesmo que a preocupaçáo do MP com a temática possa estar relacionada a uma omissão entendida de modo amplo, nos contextos de firmamento, os TACs não parecem ser consequência de caso específico de omissão. Nesse sentido, mostram-se relevantes outras variáveis, em grande parte ligadas às condiçóes institucionais das comarcas e, possivelmente, ao perfil de cada promotor de justiça.

Entretanto, permanece a questão: os TACs são capazes de promover mudanças relevantes na dinâmica da política pública? Nessa perspectiva, vale constatar que o MP centra atençáo na pré-escola, enquanto ocorre maior ampliação no âmbito da creche. Ainda que este seja efeito positivo de exigibilidade do direito de modo amplo, não advém de uma atuação centrada na subetapa. Entende-se a escolha da instituiçáo em concentrar esforços na pré-escola, visto que a universalizaçáo deveria ter sido atingida em 2016. Entretanto, contraria-se a concepção integral da etapa, além de apontar para efeitos limitados da referida atuaçáo, haja vista os dados de matrícula. Em todo caso, percebe-se cenário relevante de uso desse instrumento coletivo de exigibilidade, com vistas ao controle da atuaçáo do poder público, que vem carregado de potencialidade e limitaçôes, a serem analisadas em trabalhos futuros. 


\section{Notas}

1. "O direito público subjetivo confere ao indivíduo a possibilidade de transformar a norma geral e abstrata contida num determinado ordenamento jurídico em algo que possua como próprio" (DUARTE, 2004, p. 113).

2. Disponível em: <http://www.transparencia.mppr.mp.br/>. Acesso em: 29 jun. 2015.

3. Municípios de pequeno porte 1: até 20.000 habitantes; municípios de pequeno porte 2: de 20.001 até 50.000 habitantes; municípios de médio porte: de 50.001 até 100.000 habitantes; município de grande porte: de 100.001 até 900.000 habitantes (IBGE, 2011).

\section{Referências}

BARROSO, L.R. Post Scriptum: Judicialização, ativismo judicial e legitimidade democrática. In: _. O controle de constitucionalidade no direito brasileiro: Exposição sistemática da doutrina e análise crítica da jurisprudência. São Paulo: Saraiva, 2009. p. 331-346.

BERCLAZ, M.S. A Corregedoria-Geral do Ministério Público e a necessidade de (re) definiçáo do seu papel de orientação e fiscalização dos membros no compromisso de cumprimento e concretizaçáo do planejamento estratégico institucional. De Jure, Belo Horizonte, n. 15, p-481-296, jul./dez. 2010.

BRAGA, D.B.G. Direito à educação e o Ministério Público do Pará - sua atuação como agente fiscalizador. 234f. Dissertação (Mestrado em Educação) - Universidade Federal do Pará, Instituto de Ciências da Educação, Belém, 2010.

. Lei no 8.069, de 13 de julho de 1990. Dispóe sobre o Estatuto da Criança e do Adolescente e dá outras providências. Diário Oficial [da] República Federativa do Brasil, Brasília, 16 jul. 1990. Disponível em: <http://www.planalto.gov.br/ccivil 03/leis/L8069.htm>. Acesso em: 20 dez. 2015.

DAMASCO, D.G. de. O Direito à Educação: A atuação das promotorias de justiça e de defesa da educação do Ministério Púbico do Distrito Federal e territórios, entre 2001 e 2007. Dissertação (Mestrado em Educação) - Universidade de Brasília, Brasília, 2008.

DUARTE, C.S. Direito Público Subjetivo e Políticas Educacionais. São Paulo em Perspectiva, v. 18, n. 2, p. 113-118, 2004. Disponível em: <http://www.scielo.br/pdf/spp/ v18n2/a12v18n2.pdf >. Acesso em: 17 dez. 2015.

Politicas Públicas: A responsabilidade do administrador e o ministério público. São Paulo: Max Limonad, 2000.

INSTITUTO NACIONAL DE ESTUDOS E PESQUISAS EDUCACIONAIS ANÍSIO TEIXEIRA (INEP). Diretoria de Estudos Educacionais (DIRED). Plano Nacional de Educaçâo PNE 2014-2014: Linha de Base. Brasília: INEP, 2015.

Sistema de consulta a matrícula do censo escolar 1997-2016. Brasília: INEP, 2016. Disponível em: <http://matricula.educacenso.inep.gov.br/>. Acesso em: 10 nov. 2016. 
INSTITUTO BRASILEIRO DE GEOGRAFIA E ESTATÍSTICA (IBGE). Indicadores Sociais Municipais. Rio de Janeiro: IBGE, 2011. Disponível em: $<$ https://biblioteca.ibge. gov.br/visualizacao/livros/liv54598.pdf>. Acesso em: 12 out. 2016.

. Paraná. Brasília: IBGE, 2016. Disponível em: <https://cidades.ibge.gov.br/brasil/ pr>. Acesso em: 10 nov. 2016.

PARANÁ. Ministério Público. Termo de compromisso de ajustamento de conduta (minuta). Curitiba: Ministério Público, 2011.

. Termo de compromisso de ajustamento de conduta. Araucária, 2015.

$\overline{\text { Curiúva, }} \cdot \frac{}{2014 \mathrm{a} .}$. Termo de compromisso de ajustamento de conduta (município de Figueira).

Termo de compromisso de ajustamento de conduta. Campo Mourão:

Ministério Público, 2014b.

Dados coletados a partir de material fornecido diretamente pela Subprocuradoria Geral de Planejamento Institucional do Ministério Público do Paraná. Curitiba: Ministério Público do Estado do Paraná, 2016. [acesso restrito]

Portal da transparência do Ministério Público do Paraná. Curitiba: MP-PR. Disponível em: <http://www.transparencia.mppr.mp.br/>. Acesso em: 09 set. 2016.

RIZZI, E.; XIMENES, S.B. Ações em defesa do direito à educação infantil em São Paulo: litigância estratégica para a promoção de políticas públicas. In: TERRA DE DIREITOS (Org.). Justiça e direitos humanos: experiências de assessoria jurídica popular. Curitiba: Terra de Direitos, 2010.

RODRIGUES, G. de A. Ação civil pública e termo de ajustamento de conduta: teoria e prática. Rio de Janeiro: Forense, 2002.

ROSEMBERG, F. A educação pré-escolar obrigatória: versão preliminar. Texto preparado como trabalho encomendado pelo Grupo de Trabalho Educação de Crianças de 0 a 6 anos da ANPED. In: REUNIÃO ANUAL DA ANPED, 32., 2009, Caxambu. Caxambu: ANPEd, 2009.

Análise das discrepâncias entre as conceituaçóes de Educação Infantil do Inep e do IBGE: sugestóes e subsídios para uma maior e mais eficiente divulgação dos dados. In: ARTES, Amélia; UNBEHAUM, Sandra (Orgs.). Escritos de Fúlvia Rosemberg. São Paulo: Cortez, 2015.

. Educação infantil, classe, raça e gênero. Cadernos de Pesquisa, São Paulo, n. 96, p. 58-65, 1996.

SADEK, M.T. Cidadania e Ministério Público. In: SADEK, M.T. (Org.). Justiça e cidadania no Brasil. Rio de Janeiro: Centro Edelstein, 2009. Disponível em: <http://books.scielo.org/ id/rrwrz>. Acesso em: 24 out. 2015.

SANTOS, B. de S. Para uma revolução democrática da justiça. 3. ed. São Paulo: Cortez, 2011.

SILVA, C.A. Justiça em Jogo: Novas facetas da atuação dos promotores de justiça. São Paulo: Editora da Universidade de São Paulo, 2001. 
SILVA, E.P.I.D. da. Os efeitos da atuação do sistema de justiça nas políticas de Educação Infantil: estudo de caso no município de Araucária/PR. 158f. Dissertação (Mestrado em Educação) - Universidade Federal do Paraná, Curitiba, 2016.

SILVEIRA, A.A.D. A exigibilidade do direito à educação básica pelo Sistema de Justiça: uma análise da produção brasileira do conhecimento. Revista Brasileira de Política e Administração da Educação, v. 24, n. 3, p. 537-555, set./dez. 2008. https://doi. org/10.21573/vol24n32008.19271

Direito à educação e o Ministério Público: uma análise da atuação de duas Promotorias de Justiça da Infância e Juventude do interior paulista. 262f. Dissertação (Mestrado) Faculdade de Educação, Universidade de São Paulo, São Paulo, 2006.

Possibilidade e limites da judicialização da educação: análise do Sistema de Justiça do Paraná. Relatório técnico da pesquisa financiada pelo CNPq, chamada MCTI/CNPq/ MEC/Capes no 18/2012. Curitiba: UFPR, 2015.

SILVEIRA, A.A.D.; GONÇALVES, L.F. Proteção do direito à Educação Infantil por meio da atuação do Ministério Público do estado do Paraná. In: SIMPÓSIO LUSOBRASILEIRO EM ESTUDOS DA CRIANÇA, 2., 2014, Porto Alegre. Porto Alegre: UFRGS, 2014.

TORRES, R.L. O Direito ao Minimo Existencial. Rio de Janeiro: Renovar, 2009.

VICTOR, R.A. de. Judicialização de Políticas Públicas para a Educação Infantil: características, limites e ferramentas para um controle judicial legítimo. São Paulo: Saraiva, 2011.

VIOLIN, J. Protagonismo judiciário e processo coletivo estrutural: o controle jurisdicional de decisóes políticas. Salvador: Editora Jus PODIVM, 2013.

ZANDER, K.F. Judicialização da política do corte etário para o ingresso no ensino fundamental no Paraná. 171f. Dissertação (Mestrado em Educação) - Universidade Federal do Paraná, Curitiba, 2015. Disponível em: <http://hdl.handle.net/1884/41911 >. Acesso em: 10 abr. 2016.

Recebido em 07 de outubro de 2017.

Aceito em 01 de março de 2018.

(C) 2018 Centro de Estudos Educação e Sociedade - CEDES Este é um artigo de acesso aberto distribuído nos termos de licença Creative Commons. 